\title{
NORBERT ELIAS E MOZART COMO OUTSIDERS: MEMÓRIAS DE INFÂNCIA E FIGURAÇÃO SOCIAL ${ }^{1}$
}

\author{
NORBERT ELIAS AND MOZART AS OUTSIDERS: \\ CHILDHOOD MEMORIES AND SOCIAL FIGURATION
}

\author{
NORBERT ELIAS Y MOZART COMO OUTSIDERS: MEMORIAS \\ DE LA INFANCIA Y FIGURACIÓN SOCIAL
}

\author{
Magda SARAT ${ }^{\mathrm{I}}$ \\ Renato SutTANA ${ }^{\mathrm{I}}$
}

Resumo Inspirando-se na obra teórica de Norbert Elias, as ciências humanas têm avançado nos diferentes contextos investigativos, com desdobramentos importantes e variados. O presente artigo é um recorte de pesquisas que temos desenvolvido sobre temas como memória, infância e literatura, com base numa fundamentação teórica elisiana. Particularmente, temos recorrido às contribuições desse pensador para tratar, em especial, os temas da educação e da formação dos indivíduos desde a infância. Neste artigo, utilizando como fontes as obras do próprio Elias e textos biográficos de comentadores, buscaremos elementos que ajudem a compreender a pessoa desse sociólogo brilhante, que no entanto foi considerado um outsider ao longo de sua trajetória humana e intelectual. Sugestionados pelo livro Mozart: sociologia de um gênio, no qual Elias, ao escrever sobre o músico austríaco, revela traços de sua própria personalidade, queremos analisar e enfocar essa trajetória, com ênfase especial nas memórias de infância, às quais Elias recorre para externar suas percepções sobre os outsiders, tema fundamental de suas postulações. Estudaremos também o modo como o conceito de outsider, na modernidade, indica o lugar social do indivíduo no processo civilizador e nos diferentes grupos, marcando as trajetórias coletivas e individuais dos seres humanos.

Palavras chave: Norbert Elias — Memória - Infância - Estabelecidos e Outsiders

UFGD. Dourados, MS, Brasil

Pesquisa desenvolvida com apoio da CAPES- FUNDECT - Fundação de Apoio ao Desenvolvimento do Ensino, Ciência e Tecnologia do Estado de Mato Grosso do Sul. 
Abstract Inspired by Norbert Elias' theories, the human sciences have advanced in different research contexts, with important developments. This article is a review of a research we have developed on themes such as memory, childhood and literature, based on an Elisinian theoretical background. Specifically, we turn to the contributions of this German thinker to address such themes as Education and training of individuals from childhood. Based on sources as the works of Elias and some biographical texts of commentators, we try to search for elements that can help us to understand this brilliant sociologist as an individual and as a person who nevertheless was considered an outsider throughout his human and intellectual development. Starting from the book Mozart: Sociology of a Genius, in which Elias - writing about the Austrian musician — reveals traces of his own personality, we carry on an analysis focused on his trajectory, specially emphasizing his childhood memories, to which Elias resorted in order to express his perceptions about the outsiders - one of the fundamental themes of his postulations. We also study how the concept of the outsider, modernly, indicates the social place of the individual in different groups in the civilizing process. This experience marks the collective and individual trajectories of all human beings.

Keywords Norbert Elias - Memory - Childhood - Established and Outsiders

Resumen La obra de Norbert Elias ha sido la base teórica de investigaciones en diferentes contextos de las ciencias humanas, resultando en importantes y distintos avances. El presente artículo forma parte de investigaciones sobre temas como memoria, infancia y literatura, que hemos llevado a cabo desde una fundamentación teórica en la obra elisiana. Hemos buscado las contribuciones de dicho pensador especialmente para investigar las temáticas de la educación y de la formación de los individuos desde la infancia. En este trabajo nos hemos basado en las obras de Elias y en textos biográficos de sus estudiosos, para buscar elementos que nos ayuden a comprender la persona que fue ese brillante sociólogo; a su época, considerado como un outsider a lo largo de su trayectoria humana e intelectual. Motivados por el libro Mozart: sociología de un genio, en el cual Elias, mientras escribe sobre el músico austríaco, revela rasgos de su propia personalidad, pretendemos analizar y poner de relieve esa trayectoria, enfatizando especialmente sus memorias de infancia, usadas por el autor para la exposición de sus percepciones respecto a los outsiders, un tema fundamental de sus postulados. Estudiamos también cómo el concepto de outsider, en la modernidad, indica el lugar social del individuo en el proceso civilizador y en los diferentes grupos y cómo señala las trayectorias colectivas e individuales de los seres humanos.

Palabras clave: Norbert Elias - Memoria - Infancia - Figuración - Establecidos y Outsiders

\section{INTRODUÇÃo}

"Minha memória ainda é bastante boa, embora eu já viva há tempo demais. O desejo de me recordar talvez tenha se acentuado nos anos recentes."

(Elias, 2001, p. 10) 
Lembrar a infância e rememorar as experiências passadas é um exercício que fazemos cotidianamente, em diferentes situações, e foi também um exercício praticado por Norbert Elias, conforme o próprio autor o declara nessa epígrafe, cujo texto faz parte de uma longa entrevista concedida por ele em 1984 a A. J. Heerma van Voss e A. van Stolk. Na entrevista, o autor conta sua história de vida e fala de sua trajetória e formação. Trata-se, pois, do que hoje chamamos de uma experiência de história oral, composta, neste caso, de sete entrevistas concedidas a Van Voss e Van Stolk ao longo de vários dias e em diferentes lugares. Totalizam-se cerca de vinte horas de gravação, que, após transcritas e aprovadas pelo autor, se transformaram num livro cujo título original, em alemão, é Norbert Elias über sich selbst ${ }^{2}$, de 1990. A entrevista, realizada quando Elias já alcançara seus 87 anos — ou seja, quase ao final de sua vida (considerando que faleceu em 1990) — é um presente aos leitores que desejam se aproximar e conhecer o legado desse pensador que, conforme é consenso reconhecer, influenciou diversos autores ${ }^{3}$, trazendo contribuições consideráveis à sociologia e às ciências humanas em geral.

No Brasil, esse material está publicado sob o título de Elias por ele mesmo (2001). Na na versão espanhola, aparece como Mi trajectoria intelectual (1995b). Tal obra fornecerá a base para o presente estudo, que se baseia principalmente naquilo que Elias disse de si próprio. A ela, no entanto, somaremos outros escritos do autor (vide Elias, 1993; 1994a; 1994b; 1995a; 1995b; 1998; 2001), que nos permitirão propor uma aproximação à pessoa e ao pensamento desse sociólogo cujo trabalho só se difundiu no final do século XX, ganhando impulso no início do século XXI, mesmo tendo sua produção se estendido, intensamente, ao longo de quase todo o século XX, desde o surgimento de sua obra capital, em 1939, sob o título de $O$ processo civilizado, até a publicação da entrevista, um dos últimos textos do autor aparecidos em vida.

Na obra autobiográfica - embora tenha se restringido a tratar somente de temas atinentes à sua trajetória intelectual (e, nesse sentido, o título em espanhol se mostra bastante pertinente) -, também encontramos, além de fragmentos de memórias da infância, diversos insights sobre o modo como o autor percebia, já em sua velhice, os diferentes aspectos de sua vida cotidiana e familiar, sobre os quais discorre em diversos pontos. Tais experiências, que remetem a uma reflexão sobre o processo da educação e formação humana e intelectual de Elias, nos interessam diretamente neste artigo, pois intentamos aqui não só apontar o lugar da infância na formação e nas percepções do pensador Elias, como também, abrindo o leque da reflexão, pensar com Elias na condição de todos os indivíduos nas sociedades ditas modernas.

Outro aspecto que nos interessa, ao nos debruçarmos sobre suas memórias, está expresso no modo como Elias concebe a arquitetura de seu conhecido livro Mozart: sociologia de um gênio $\left(1995^{\mathrm{a}}\right)$, considerado por amigos e pessoas próximas ao autor (conforme

2 Aproximadamente, o título significa "Norbert Elias [fala] sobre si mesmo", traduzido em português como Elias por ele mesmo (vide bibliografia).

3 Entre os quais se destacam as figuras de Pierre Bourdieu, Roger Chartier, Anthony Giddens e Zygmunt Bauman, para ficarmos em alguns dos mais conhecidos. 
o anotam alguns de seus comentadores ${ }^{4}$ ), como um livro também autobiográfico, no qual o sociólogo expressou alguns sentimentos e concepções acerca de sua própria trajetória. Nessa obra, a tese que Elias desenvolve é de que Mozart ${ }^{5}$ "desistiu" da vida ${ }^{6}$ e morreu de depressão, por não se ver aceito numa sociedade de corte — que foi aquela com que Mozart conviveu no século XVIII — cujos códigos eram fechados e sem mobilidade. Segundo Elias, qualquer que tenha sido a doença que contribuiu para o falecimento prematuro do músico (morto 1791, aos 35 anos), o fato é que Mozart

várias vezes esteve próximo do desespero. Aos poucos, foi se sentindo derrotado pela vida. Suas dívidas aumentavam. A família se mudava de um lugar para o outro. O sucesso em Viena, que para ele talvez significasse mais do que qualquer outro, jamais se concretizou. A alta sociedade vienense deu-lhe as costas. (...) Sem dúvida alguma, morreu com a sensação de que sua existência social fora um fracasso. (Elias, 1995a, p. 9).

O grupo social de que o músico participava provavelmente não via nele as capacidades criativas e os atrativos do gênio musical que se tornaria referência para toda a música posterior no Ocidente. É possível, ao ler as cartas de Mozart, supor que tivesse consciência do seu valor como artista e da sua obra musical; mas, segundo Elias, ele se viu obrigado a aceitar a sua condição de burguês numa sociedade de corte, trabalhando como um "empregado" do Rei e por isso tendo de se submeter aos ditames de uma hierarquia rígida e constritora, dentro da qual as aspirações a uma liberdade humana e criativa amplas — reivindicadas já no tempo de Mozart pelo movimento Sturm und Drang (Tempestade e Ímpeto) ${ }^{7}$, do qual Johann Wolfgang von Goethe e Friedrich Schiller seriam os corifeus - não podiam ser aceitas. Tal situação o fez viver, pois, conforme a descrição de Elias, na condição de um outsider durante toda a sua curta existência, incluindo-se entre os males que teve de suportar a saúde frágil e o processo depressivo no qual mergulhou mais profundamente nos últimos anos. Argumentando em defesa da tese, Elias acrescenta:

Hoje, quando o simples nome de Mozart para muitos se tornou símbolo do maior prazer musical que nosso mundo conhece, pode parecer incompreensível que um homem dotado de tais poderes mágicos de criatividade pudesse ter encontrado morte prematura - porque a falta de amor e generosidade das pessoas aprofundou as suas dúvidas quanto ao valor e o significado de sua vida. Pode parecer especialmente difícil acreditar-se nisto quando o interesse é apenas por sua obra, e não pelo ser humano que a criou. (Elias, 1995a, p. 9-10)

4 Aqui destaco algumas biografias e apresentações de seus textos feitas por autores como Zabludovsky, 2007, 2009; Weiler, 1998; Gebara, 2005; Gebara \& Wouters 2009; Quintaneiro, 2010; Heinich, 1999, 2001; Kaplan, 2008; Kaplan \& Orce, 2009; Perez Rivera, 2010; Manz, 2012 e Sarat, 2008, 2005 e 2014, entre outros. (Vide a bibliografia deste artigo.)

5 Wolfgang Amadeus Mozart (batizado como Johannes Chrysostomus Wolfgangus Theophilus Mozart) nasceu em Salzburgo em 27 de janeiro de 1756 e morreu em Viena a 5 de dezembro de 1791.

6 O título do primeiro capítulo, que serve de introdução ao livro, é "Ele simplesmente desistiu".

7 O movimento se situa entre os anos de 1760 e 1780, sendo, portanto, contemporâneo de Mozart, que dele deve ter tido algum conhecimento. 
Nesse particular, o pensamento de Elias desafia o leitor a pensar também no indivíduo, isto é, no ser humano empírico que Wolfgang Amadeus Mozart foi, antes de ser o gênio musical que o mundo reconheceu. Mas também - seguindo o fio de sua reflexão sobre o músico vienense e do que ela contém de revelações sobre si mesmo - , de modo geral, nos leva a pensar nos indivíduos que nos tornamos ao longo da nossa formação. Este é o objeto da presente reflexão: enxergar o indivíduo imerso na teia de relações com que o envolve a sociedade e com a qual estabelece laços de dependência que perfazem todos os níveis da vida, considerando-se desde aqueles que se afirmam a partir da infância (tomada como tempo crucial e marcante, no qual um certo padrão de percepção da experiência se estabelece, fundando o modo de senti-la e lidar com ela que, ao longo dos anos, se constituirá em sua identidade no âmbito da cultura e do grupo social de que faz parte), até aqueles da idade madura (no caso de Mozart) ou da velhice (no caso de Elias). Segundo essa concepção, é possível dizer que, participando de um grupo desde que nascemos, nosso ser se dá como o encontro entre a experiência individual e os padrões de comportamento e códigos sociais a que somos expostos. E é com base nas figurações sociais que se imprime em nós uma parte da nossa formação e das concepções sobre o mundo que construiremos ao longo da vida. Assim, nossas experiências de memória, nossos sentimentos, mas também nossos ressentimentos e desgostos, serão construídos a partir desse momento inicial, desenvolvendo-se então conforme o modo como se configure o leque de experiências pelas quais, como indivíduos, teremos de passar ao longo de nossa trajetória.

No sentido de organizar a discussão - e uma vez que nos interessa falar não só do homem Elias em particular, na sua experiência individual, mas também de sua concepção da relação estabelecido/outsider como determinante da posição dos indivíduos nas redes de poder social —, dividiremos a reflexão em três partes: na primeira, falaremos dos aspectos da biografia de Elias e de sua história de vida desde a infância; na segunda, trataremos do lugar de Mozart como um outsider em seu tempo, propondo um diálogo com a percepção (sociológica) que Elias tem da sua própria trajetória; e, finalmente, abordaremos o conceito de outsider, buscando não somente entender o seu significado na obra do sociólogo, mas estendê-lo para falar da modernidade em geral, marcada por noções de liberdade e autonomia individual, que demandam um ser humano incluído e aceito socialmente.

\section{NORBERT ELIAS: MEMóRIAS DA INFÂNCIA E OUTRAS HISTÓRIAS}

"Viam-se muitas crianças... eu também ia para brincar de bambolê ou outros jogos com as demais crianças."

(Elias, 2001, p. 11)

Considerado atualmente como um dos sociólogos mais importantes do século XX e reconhecido em virtude da extensão e profundidade das suas teorias, Elias tem muito contribuir com a reflexão sobre o indivíduo contemporâneo. Particularmente, teve uma formação ampla e erudita, que abrangeu diferentes áreas de conhecimento, tais como a medicina, a filosofia, a psicologia, a história, a literatura e as artes, além de outros campos pelos quais 
se interessou. Nascido em Breslau ${ }^{8}$ a 22 de junho de 1897, e falecido em Amsterdã a $1^{\circ}$ de agosto de 1990, Norbert Elias viveu uma vida que hoje consideramos longa, além de intelectualmente profícua, com sua duração de quase um século. No campo intelectual, esteve sempre envolvido com a produção de um conhecimento que o levasse a compreender os seres humanos na sociedade e os diversos modos como os indivíduos vivenciam processos civilizacionais e relacionais em seus grupos sociais.

Como judeu não-praticante (pois se declarava, quanto ao judaísmo, "isento do seu sinal manifesto mais distintivo, a religião"), Elias - pertencendo a um grupo social que, historicamente, passou por vários contextos de diáspora - , na época em que adquiriu sua primeira formação, viveu numa região de cultura absolutamente germânica ou, segundo suas palavras, "completamente alemã [e que] não tinha nada de polonesa" (ELIAS, 2001, p. 13). Portanto, suas primeiras experiências de vida se deram no bojo de mais de um contexto identitário ou espaços sociais em disputa:

É bastante provável que as experiências por que passei como judeu, na Alemanha, desde minha primeira infância, tenham contribuído para reforçar a atração que senti mais tarde pela sociologia. Culturalmente muito ligado à tradição alemã, eu pertencia pela estrutura de minha personalidade a um grupo minoritário desprezado. (...) Mais tarde, incluí muitos aspectos dessas experiências em uma teoria sociológica, a teoria das relações entre grupos estabelecidos e grupos outsiders. (Elias, 2001, p. 135)

A respeito de sua origem, os biógrafos destacam o fato de Elias ter sido o único rebento de uma família de judeus abastados e bem estabelecidos na sociedade alemã do final do século XIX. No entanto, Elias perdeu os pais no contexto das perseguições aos judeus da Alemanha e da Polônia na época nazista: Hermann Elias, seu pai, morreu em 1940, em Breslau; e sua mãe, Sophie Elias, foi assassinada em Auschwitz, talvez em 1940 (?). Segundo Elias, seu último encontro com os genitores ocorreu em 1938, quando já vivia em exílio na Inglaterra. Disso o autor se ressente profundamente, lamentando ainda o fato de não ter podido convencer os pais a abandonar a Alemanha no período da perseguição: “(...) eu não podia forçá-los. Foi a última vez que vi meus pais. Ainda lembro perfeitamente... É claro que nunca consegui superar isso" (Elias, 2001, p. 61). A descrição que faz do último encontro com Hermann e Sophie é bastante emocionada, revelando até que ponto esse evento fundamental marcaria a sua existência como homem e pensador:

Vi-os pela última vez em 1938, quando foram me visitar em Londres. Implorei
para que viessem se instalar comigo na Inglaterra, mesmo a situação financeira
sendo um pouco difícil. Para meu pai, era inconcebível, e minha mãe, fiel à
sua natureza, ficou do seu lado. Jamais esquecerei as palavras com as quais ele
refutou minha observação sobre a brutalidade dos nazistas: "O que podem me
fazer?, disse, nunca fiz mal a ninguém, nunca, ao longo de toda minha vida,
infringi a menor lei." (Elias, 2001, p. 140)

Na época, a cidade pertencia ao Império Alemão, e hoje está incorporada ao território da Polônia. 
Esses dois aspectos, sempre presentes nas biografias, são importantes, pois indicam, além do lugar (geográfico e social) de onde veio, também a centralidade de suas referências familiares e culturais na sua formação e no seu pensamento.

Neste artigo, a infância de Elias é apresentada com base em sua própria rememoração, expressa na entrevista citada, mas também em outros documentos, tais como cartas pessoais e declarações de vária ordem, onde encontramos outras referências. Esse aspecto indica que, a exemplo de Mozart, Elias foi uma criança "prodigiosa", no âmbito daquilo que the interessava diretamente - o conhecimento científico, filosófico e literário, para o qual se voltou em época precoce - ; e essa experiência embasaria depois a sua a reflexão sobre as relações sociais, a distribuição do poder e a posição do indivíduo naquilo que chamou de figurações sociais, conceito chave de sua teoria.

Quanto ao caso de Mozart, como os seus biógrafos assinalam, ganhou foros de lenda o fato de ter escrito aos cinco anos a sua primeira peça musical, o que mostra tanto a dimensão precoce do seu talento, quanto a presença da música como motivo central de toda a sua vida. Já Elias exibiu desde cedo um interesse por temas que extrapolavam o universo de interesses da sua idade, conforme ele mesmo reconhece, tendo aprendido a ler muito cedo, entre os 6 e 7 anos, mergulhando em livros cuja leitura não era comum para as crianças do seu tempo: “(...) comecei a ler muito cedo, mergulhava em todo tipo de livro. Nessa época eu também devia ter seis ou sete anos" (Elias, 2001, p. 11).

Sua infância foi cercada de cuidados, conforme conta. Era uma criança frágil, embora inteligente, que imergiu precocemente na experiência de estudar arte, literatura e música. Por essa razão, estava sempre aos cuidados de babás, tendo forte presença da mãe no atendimento das suas necessidades. Sobre a mãe, da qual se lembra e fala sempre com admiração, Elias diz que "era a melhor mãe que se possa imaginar, uma mulher completa, de bem com a vida" (Elias. 2001, p. 11). Além disso, tinha uma família extensa, com avós, tios e grande parentela de indivíduos que se visitavam frequentemente.

A educação formal começou em casa, com o aprendizado da leitura e da escrita, antecipando a formação escolar. Segundo declara, quando precisava convalescer de alguma enfermidade, passava longos períodos em casa, o que obrigava os pais a pagarem professores particulares: "Eu era filho único, e pegava todas as doenças infantis que uma criança pode pegar. Daí meus pais me acharem muito frágil para entrar diretamente no curso preparatório. Lembro muito bem que eles arranjaram aulas particulares" (Elias, 2001, p. 11). Desse modo, as experiências com um tipo de leitura e de literatura que hoje consideramos imprópria para crianças de idade tenra marcaram a sua formação inicial. Elas são lembradas, inclusive, numa passagem especial em que fala da cerimônia do seu Bar-Mistva ${ }^{9}$, época em que começou a ler os clássicos da literatura alemã. Tal aspecto - o convívio com os clássicos - pode ter contribuído, é de suspeitar, para reforçar a sua identificação como

9 Cerimônia judaica que insere o menino (entre os 12 e 13 anos) na comunidade. Segundo Elias a sua ocorreu com a idade de 13 anos: "(...) segundo a tradição judaica, fui recebido na comunidade dos adultos em uma cerimônia ritual na sinagoga, seguida de uma festa na casa de meus pais. Esse evento correspondia às normas de uma sociedade que remontava a um estágio de desenvolvimento bem mais antigo. Os ritos religiosos permaneciam imutáveis" (Elias, 2001, p. 95). 
indivíduo alemão, ao mesmo tempo em que se via em contato com elementos da cultura judaica tradicional, com os seus rituais e os seus modos de comportamento específicos. Nas palavras de Elias:

Sabia que vários parentes e amigos me dariam um presente por ocasião da festa. (...) a maioria iria a uma grande livraria de Breslau para encontrar livros convenientes à criança que eu era. Por precaução, uma semana antes fui a essa livraria, onde exprimi o desejo de que insinuassem a todas as pessoas que procurassem um presente apropriado para o bar-mistva de Elias, que o jovem em questão esperava que lhe ofertassem autores alemães clássicos na edição do Instituto Bibliográfico. Eu já possuía obras completas de Schiller, e ganhei as de Goethe, Heine, Mörike, Eichendorff e outros autores da mesma coleção. (Elias, 2001, p. 95).

Sobre essa experiência - que se assemelha, em precocidade, ressalvadas as diferenças de cada experiência individual e de cada campo de atuação, àquela do Mozart menino compondo as suas primeiras peças musicais - Elias afirma que, por certo, o contato com a literatura clássica alemã teve influxo determinante na sua formação. No que diz respeito ao desenvolvimento pessoal, credita a essas leituras um aspecto da extensão e a profundidade de sua abordagem dos problemas humanos e das teorizações que se desdobram ao longo de sua vasta obra: "Goethe, Schiller, Kant, eis meus grandes homens. Meu primeiro ensaio publicado está cheio de referência a esses homens”, escreve (Elias 2001, p. 26). No entanto, é conveniente lembrar que a cerimônia do Bar-Mitzvah, à qual se reporta, em sendo uma experiência da infância, concernente à passagem da criança à puberdade — ou, nos termos atuais, à pré-adolescência —, não é lembrada, propriamente, como experiência de cunho religioso e iniciático. Antes, aparece como experiência secundária, do adolescente que, aos doze ou treze anos, debruçado sobre um corpo de leituras densas e complexas, encontrou nela o pretexto para outra, de caráter mais fundamental, a implicar o acesso a uma literatura que hoje se consideraria excessiva para a sua idade.

Não obstante, no fragmento citado o próprio autor, ao dizer que o garoto, em véspera do seu Bar-Mitzvah, já possuindo as obras completas de Schiller, segundo declara, se rejubila em ganhar de presente as de Goethe, Heine, Mörike e Eichendorff, expressa o fato, estranho aos nossos dias, de que os livros pedidos na ocasião - sem considerações acerca de sua adequação ou inadequação à idade (que são próprias do nosso tempo) — podiam estar de acordo com o interesse das crianças de sua faixa etária. Pelo menos, estavam de acordo com o interesse de um menino chamado (Norbert) Elias, poupando-lhe, segundo reconhece, o trabalho "de trocar um grande número de livros" (2001, p. 95). A questão se impõe naturalmente, ao observarmos, por exemplo, o receio que a criança tinha de que não lhe fossem dados os livros em questão ou de que lhe servissem literatura considerada própria à sua idade, qualquer que fosse, ou que apenas fizesse parte do imaginário estudantil dos contemporâneos. Aqui, o fragmento sugere que o garoto Elias não se interessava pelas mesmas coisas que os demais e, por isso, precavido, se adiantou em procurar uma literatura do seu interesse, não representando esta, necessariamente, o interesse da infância ou de sua idade. 
Com efeito, não se trata aqui de comparar talentos ou de sugerir que a experiência de Elias, em seu campo, deva ser equiparada à de Mozart, cuja importância para o universo da música tem outro teor e outra configuração (até porque o que sabemos da experiência infantil de Elias é só aquilo que ele mesmo relata). Não se trata também de entender a experiência juvenil do sociólogo sob a luz do mito da criança "prodígio", que cerca a biografia de Mozart e parece ser - não obstante o seu caráter de mito — tão cara à época contemporânea. Queremos, antes, sugerir que determinados elementos de sua própria biografia parecem ser interpretados por Elias com base em certos aspectos da biografia de outrem, recebendo assim uma significação que reforça o nosso ponto de vista sobre o caráter outsider que Elias descobre em sua experiência. Do ponto de vista sociológico, importa-nos ressaltar essa descoberta, pois nos ajuda a compreender melhor o par conceptual que Elias desenvolve, ao confrontar os termos estabelecido e outsider, no bojo da sua teoria.

Quanto a esse episódio - que nos faz indagar sobre aquilo que os meninos e adolescentes do final do século XIX liam e que não era capaz de despertar o interesse do autor podemos afirmar que somente um número pequeno de crianças tinha acesso à escolarização e ao aprendizado da leitura em idade jovem, mesmo na Europa do final do século XIX. Assim, não é exagero presumir que Elias fosse uma criança "diferenciada" das demais, seja por seus interesses e inclinações, seja pelo contexto social e cultural a que pertencia, responsável este pela definição e pelo modo como ele mesmo interpretava os seus gostos. Na entrevista, o autor conta que da janela de seu apartamento costumava observar as crianças brincando na rua, no parque em frente à sua casa. Menciona também o hábito de relacionar-se com crianças pertencentes a outros contextos sociais, tais como os filhos de uma zeladora (que morava no porão do seu prédio) ou as crianças pobres que frequentavam o parque - ocasião que lhe permite relatar um aspecto de sua infância, relacionado à prática de brincadeiras e jogos comuns ao período.

No caso de Mozart, pode-se dizer que também foi — de um modo mais acentuado uma criança "diferente" das contemporâneas. Alguns aspectos de sua infầncia aparecem nas biografias ${ }^{10}$, sendo relembrados, aqui e ali, na obra do próprio Elias (especialmente em Mozart: sociologia de um gênio, onde o sociólogo se detém no fato de que o músico foi educado pelo pai, um "burguês da corte", com o fito de se adequar a certas exigências do mundo cortesão de seu tempo). Considerado já no século XVIII como uma criança prodígio, pelas habilidades de virtuosismo que demonstrava em sua pouca idade, Mozart se destacou como o que atualmente chamaríamos de um "fenômeno" infantil. Viveu, por certo, num período histórico no qual, na concepção de Ariès (1981), as crianças eram percebidas de outro modo que o atual, em que tentamos vê-las como seres em si, com suas necessidades e demandas próprias, e não apenas como "adultos em miniatura" (na expressão de Ariès). No tempo de Mozart, a inserção social da infância e da criança e sua percepção como ser dotado de características próprias ainda engatinhava. Tomou corpo só a partir da modernidade tardia, o que condiz com o modo opressivo e desconsiderado como Leopold Mozart introduziu o filho pequeno no universo complexo e exaustivo do virtuosismo musical.

10 Ver Blot (2015) e Padale (2004), por exemplo, na bibliografia. 
Em períodos anteriores da história, pode-se dizer que as crianças não eram "percebidas" ou não eram vistas como tais (ou como aquilo que chamamos hoje de crianças), embora tivessem, por certo, as mesmas características físicas e psicológicas das atuais ${ }^{11}$, pois não temos razão para supor que fossem diferentes. Desse modo, em seu tempo, Mozart vivenciou uma experiência diferenciada de infância (e não propriamente positiva, se a considerarmos sob a ótica moderna da psicologia e da pedagogia infantil), demonstrando habilidades de adulto desde a idade tenra - caso que seria incomum entre as outras crianças. Aos quatro anos, já executava peças complexas ao piano, instrumento de considerável complexidade, e aos cinco começou a compor os seus próprios concertos. Aos seis anos, já saiu em tournée pelos palácios e cortes da Europa (Elias, 1995a). Devido a isso, Mozart menino pode ser tomado como precursor de um modelo de criança que começou a chamar a atenção a partir do século XVIII, considerando-se os modos de conceber os pequenos e de perceber as suas capacidades na perspectiva dos adultos que a partir de então se estabeleceram. Quanto a este aspecto, no rastro de Ariès, a literatura nos informa que o conceito ou representação social da infância e de seu lugar é fruto de uma construção histórica, configurando-se a partir da percepção de suas peculiaridades próprias: grosso modo, numa pauta negativa ou de carências nas épocas mais remotas (a criança como "adulto em miniatura" e, portanto, ser que se caracteriza mais pelo que lhe falta para tornar-se um adulto do que por suas peculiaridades); ou, contemporaneamente, numa pauta positiva ou até de saturação (a criança como indivíduo social definido não em relação ao adulto, mas em função de suas próprias características biológicas, psíquicas, cognitivas, etc.).

No entanto, voltando à aproximação entre Elias e Mozart, podemos aventar, como hipótese de base, que ambos foram expostos à exigência de estar, por assim dizer, "acima da média" em relação às competências (ou ao domínio de habilidades adultas) das crianças de seu tempo. Sobre Elias, por exemplo, na ausência de documentação externa, temos apenas o que a sua memória de ancião de 87 anos contou sobre o que ainda podia lembrar a respeito da infância; e sobre Mozart, além da literatura biográfica, temos — para os objetivos deste estudo - o livro do Elias. Quanto a este, os comentaristas apontam que, talvez inconscientemente, sua reflexão sobre o músico de Salzburgo revela aspectos autobiográficos, permitindo inferir as aproximações e identificações que se dão entre ambos os indivíduos, na perspectiva do segundo, mas com ênfase especial no aspecto da incompreensão sofrida por cada um em seu contexto social. Para nós, interessa levantar hipóteses sobre os motivos pelos quais Elias se identificava com Mozart e em quais momentos tal identificação se apresentou.

Na visão de Elias, Mozart tinha, sobretudo, consciência do próprio talento, bem como da qualidade de sua música; porém enfrentava — como tantos artistas — a indiferença e a incompreensão de seu tempo, imergindo aos poucos no ressentimento de não ser aceito por

11 É importante observar, quanto a este aspecto, que estamos a falar aqui do lugar social da criança e não da criança compreendida como ser biológico ou indivíduo cujo corpo e mente, ainda jovens, não alcançaram a maturidade que se atribui aos adultos - maturidade do corpo, no que diz respeito à biologia, e social, no que diz respeito ao domínio de certas habilidades necessárias ao trabalho, à frequentação de lugares, ao conhecimento linguístico, à constituição de família e ao provimento da própria subsistência. 
uma camada da sociedade que bloqueava os seus esforços de ascensão e inclusão. Sobre esse aspecto, Elias admite que Leopold Mozart, o pai, estava mais aparelhado para entrar no jogo da sociedade cortesã, mesmo não pertencendo à nobreza, muito porque, apesar de burguês e pobre, conhecia a regras e se sujeitava a elas, ao passo que o filho, brilhante, inquieto e inconformado, não se adaptava. Um aspecto do comportamento de Mozart que Elias salienta são os seus surtos de irreverência e inconformismo social, que se tornaram famosos no anedotário da música. Eles demonstravam, entre outras coisas, o desprezo de Mozart pelas regras de "bom comportamento" e civilidade vigentes nos meios que frequentava, em cujo âmbito o servilismo, a hipocrisia e a bajulação se impunham como traços de comportamento que deviam estar presentes para garantir e confirmar os laços de mútua dependência e consentimento. A hipótese de Elias é de que o músico, vendo-se imerso num universo de configurações sociais que ainda não inclúam o conceito do músico autônomo e livre, se revoltou contra as regras, apostando, até certo ponto, num projeto de autonomia que só se tornaria viável para a geração seguinte. Portanto, para Elias, cabe entender que o aspecto das configurações sociais é fundamental e indissociável da produção musical de Mozart, se quisermos compreender o processo de constituição dessas configurações. Sua história só pode ser entendida se considerarmos a sua pertença problemática a um sistema "fechado" de relações, que o fazia sentir-se não um estabelecido, mas um prisioneiro da corte e dos seus senhores e, portanto, um outsider.

Desse modo, é importante, para avançarmos na reflexão, observar o diálogo que se dá entre as trajetórias individuais e as configurações às quais ambos os indivíduos (biografado e biógrafo) pertenceram desde a infância, moldando nelas - no sentido de uma adaptação ou de um conflito - as suas expectativas, a sua personalidade e o seu modo de ver o mundo. Neste ponto, consideramos a infância como um período fundante na vida dos seres humanos, cujos reflexos se revelam, mais tarde, na idade adulta, nas ações dos indivíduos e no modo como superam, sucumbem ou avançam em suas experiências de aprendizado e formação - que por sua vez marcam a constituição do sujeito em seus grupos de pertença. Nesse sentido, as experiências de Elias e Mozart se aproximam tanto pelo fato de terem sido crianças cujas vivências as tornavam "diferentes" das outras (no que diz respeito à média dos comportamentos) — já que ambos aprenderem a música, a arte e a literatura comuns aos seus contextos burgueses e não propriamente à sua faixa etária -, quanto pelo fato de terem absorvido tais vivências num grau e numa profundidade que lhes permitiram, cada um a seu modo, formar a erudição (científico-sociológica para um, e musical para o outro) que se manifestou ao longo de suas trajetórias de vida. Isso gerou um conflito que as diferenças concernentes à duração do tempo de vida (longa para Elias e breve para Mozart), considerada a distância epocal em que viveram e ao tipo de relações e conflitos sociais com que se defrontaram, não camuflam.

Propomos, pois, como passo seguinte, encontrar, hipoteticamente, aproximações e distanciamentos entre os dois indivíduos. Reconhecemos, em princípio, que estamos a caminhar pelo terreno movediço da história dos afetos, dos sentimentos, do controle das emoções, dos equilíbrios afetivos, das memórias e dos ressentimentos — os quais, se nos ins- 
tigam a pensar nas suas histórias de vida, contêm um grau de obscuridade que a teoria não pode desfazer. Neste artigo, porém, mesmo desconfiados das simplificações, nos propomos a lucubrar acerca da condição de "marginais", "forasteiros" ou outsiders que foi tanto a de Mozart quanto a de Elias, irmanando-os de certo modo e, por isso, tornando-se reveladoras das relações que não só eles, mas todos os indivíduos mantêm com os seus grupos sociais e com as redes de interdependência no interior das quais se configura a experiência, consideradas as características do establishment com que cada qual se bateu no seu tempo e com que todos nos batemos. Isso é o que aproxima e distancia tais personagens. E é também o caminho pelo qual pretendemos avançar agora.

\section{Mozart e Elias: outsiders EM SEU TEMPO}

"É uma experiência singular pertencer a um grupo minoritário estigmatizado, e ao mesmo tempo sentir-se completamente inserido na corrente cultural e no destino político da maioria que o estigmatiza."

(Elias, 2001, p. 134)

Atualmente, aos olhos do mundo, Elias e Mozart aparecem como personagens históricos, de dimensões concretas, reais e reconhecidas, com suas biografias "acabadas" e passíveis de estudo e investigação — tal como se, finalmente, após a morte, abandonassem a categoria de outsiders para adentrar na de estabelecidos. Impossível, hoje, para qualquer pessoa medianamente culta, não saber quem é Mozart e, para o apreciador de música, não se emocionar com sua volumosa, rica e inspiradora obra musical. Do mesmo modo, para os estudiosos das ciências humanas, é justo ver em Elias um teórico reconhecido e influente nos diversos campos, cujas formulações inspiram o trabalho e o pensamento de muitas pessoas que, ao longo de gerações, têm se debruçado sobre as questões sociais.

Esse aspecto - atual e contundente - está a sugerir que todas as obras (como diria o próprio Elias) só podem ser bem entendidas se percebermos por trás delas o ser humano que as criou, ou seja, o indivíduo concreto que deu lhes deu vida. Não se trata só de um simples "biografismo", que tenta atribuir significados à criação (artística ou intelectual) em vista de uma personalidade empírica cujo segredo íntimo escapa à investigação. Trata-se, antes, na perspectiva sociológica, de perceber a figura em contraste contra o "fundo da cena social", isto é, inquirindo, no entorno e nos meandros da produção individual, os silenciamentos, as ausências, os desejos e as infinitas e abrangentes relações — de caráter social, afetivo, emotivo e cultural - que nela se manifestam e que foram mantidas, em vida, cotidianamente, por esses indivíduos com os seus grupos de pertença (que, no caso da epígrafe que encabeça este artigo, indica o lugar do Elias homem e pensador no mundo, demarcado pela fronteira entre duas situações: o carisma e o estigma de ser judeu e alemão no seu tempo).

Nosso desafio é, pois, discernir em quais aspectos (de experiência, personalidade e conflito com o jogo das relações sociais) se aproximam os dois personagens, os quais, cada qual no seu campo, a literatura nos apresenta como outsiders. Para Mozart a configuração de corte, no período de declínio, pode ser uma das perspectivas. No caso de Elias, defron- 
tamo-nos com a sua origem cultural e com aqueles "processos cegos" a que historicamente se viu submetido, na figuração social e no tempo histórico em que viveu, bem como nos deparamos com os acontecimentos políticos de que sofreu as consequências e sobre os quais não teve controle ${ }^{12}$.

Mozart era um burguês de corte, no dizer de Elias, que aprendeu os modos e a civilidade da aristocracia; porém não se igualava aos nobres por razões óbvias e, por isso, transitava psicologicamente numa espécie de limbo ou de zona cambiante entre o desejo de pertencer (à nobreza), fomentado por sua formação cortesã, e a sua origem burguesa. Flutuava, pois, entre a pretensão de ser aceito e admirado por esses de quem esperava reconhecimento e as injunções, concretas, reais e impermeáveis, impostas por uma relação que era a do empregado com seus patrões. Tal relação, evidentemente, confrontada pela consciência de seu próprio talento, não podia resultar senão em sentimentos permanentes de inadequação e conflito. Vivendo num espaço social de relações acabadas e fortemente hierárquicas, mesmo que decadentes (no plano econômico e no que diz respeito às chances de aceitação e status social), lutou a seu modo para se libertar da tutela de patronos e senhores. Dele se pode dizer, até, com Elias, que "sua vida ilustra nitidamente a situação de um grupo de burgueses outsiders (...) num tempo em que o equilíbrio de forças ainda era muito favorável ao establishement cortesão, mas não a ponto de suprimir todas as expressões de protesto, ainda que apenas na arena, politicamente menos perigosa da cultura" (Elias, 1995a, p. 16). Nem por isso esteve menos sujeito a ressentimentos e amarguras, a despeito de sua grande arte (ou talvez por causa dela), se considerarmos o olhar do artista cuja condição, mais e mais, com o avançar do tempo, se destaca da maioria dos indivíduos de seu grupo social.

No que diz respeito a esse ponto - da relação entre consciência artística, talento e chances de status social —, Elias abraça a versão tradicional da possibilidade de haver em Mozart uma genialidade incompreendida (e incompreensível) para o período em que viveu, apontando a necessidade de avaliarmos Mozart em relação à classe dominante do seu tempo (aquela que, por suas características de apreciadora, promotora e patrocinadora da música de alto nível, estaria mais em condições de reconhecer as qualidades do músico). Essa percepção, segundo Elias, é que fez o músico viver uma relação dicotômica entre identificar-se com a nobreza de corte (sua formação e treino), aprendendo o seu comportamento e, ao mesmo tempo, se revoltar contra esses nobres que o faziam sentir-se constantemente humilhado por não pertencer ao seu meio, não obstante (e talvez por causa dele) o seu enorme talento:

Sua situação era muito peculiar. Embora fosse um subordinado, socialmente dependente da aristocracia da corte, a clara noção do seu extraordinário talento

12 "Em cidades como Breslau, os judeus alemães constituíam uma sociedade burguesa de segunda ordem; mas, como já disse, eles próprios não se consideravam homens de segunda ordem em hipótese alguma. $\mathrm{O}$ fato de que muitos judeus não reconhecessem manifestamente a inferioridade que lhes atribuíam, o fato de que tenham se comportado frequentemente como se fossem seres iguais em direitos, provocava aliás a irritação de uma parcela importante dos membros da maioria alemã. Isso em parte explica a crítica permanente da 'impertinência' judia, que certamente reforçou os sentimentos de animosidade a respeito dos judeus" (Elias, 2001, p. 140-141). 
musical levava-o a se sentir igual, ou mesmo superior a eles. Era, numa palavra, um "gênio", um ser humano excepcionalmente dotado, nascido numa sociedade que ainda não conhecia o conceito de gênio, e cujo padrão social não permitia que em seu meio houvesse lugar legítimo para um artista de gênio altamente individualizado. (Elias, 2001, p. 24)

Mais que o aspecto da genialidade - cuja definição nos escapa por enquanto, remetendo a um âmbito de reflexões que não podemos abranger ${ }^{13}$ - , queremos apontar o lugar social do indivíduo que se ressente da falta de aceitação e do reconhecimento no interior do grupo. Sentimento e ressentimento formam, conformam e deformam os seres humanos em vários níveis e têm aspectos característicos. Com isso, podemos inferir, a partir de Elias $\left(1995^{\mathrm{a}}\right)$, que Mozart nutria um alto grau de ressentimento frente ao grupo com que se via obrigado a conviver. Tinha recebido, em criança, além de uma sólida formação musical, também uma atenção de criança "prodígio", a qual, ao crescer, foi arrefecendo ao longo dos anos, com a atrofia desse sentimento de afeição e interesse que enfim the foi negado na vida adulta, quando, aparentemente, sua música - ao mesmo tempo clássica e avançada, mas sempre sofisticada - deixou de corresponder aos gostos e interesses da corte.

Nesse contexto, para entender o modo como Mozart processou tais sentimentos, Elias recorre à documentação que deu origem ao seu livro, composta pela correspondência pessoal de Mozart com o pai, indivíduo cuja presença na vida do compositor teve consequências marcantes para o seu comportamento social e suas atitudes emocionais. As cartas trocadas entre o artista e o pai, com quem mantinha uma relação ao mesmo tempo próxima e conflituosa, informam que Mozart, em vários momentos, atribuiu parte do ressentimento com sua situação à figura paterna, da qual no entanto recebeu a formação e a educação que o habilitaram a se tornar um músico competente. Atribuiu-o também à exposição pública a que foi submetido desde seus primeiros anos. Nas cartas, Mozart revela a projeção que Leopold Mozart - um burguês de corte ambicioso, mas que nunca passou de um empregado medíocre - teve sobre o filho, dotado este de uma imaginação e de uma compreensão dos processos compositivos que raramente se encontra em outros músicos da tradição.

Discorrendo sobre essas questões, Natalie Heinich informa que Elias se propôs a revigorar a Sociologia por um método próprio, que consistiu em "descer do mais geral para o particular, atacando sem medo, o terreno da Psicologia e até da Psicanálise" (Heinich, 2001, p. 67). Ao mesmo tempo, promoveu um diálogo entre temas e disciplinas que se encontravam estanques em seus setores, amalgamando-os no que veio a ser a sua própria teoria do processo civilizador. Assim, sob esse ponto de vista, Elias convida, na opinião de Heinich, o leitor a praticar uma "pluridisciplinaridade", evocando essa autora, sobretudo,

13 No entanto, podemos dizer ao menos que, seja como for, a situação de Mozart se aproxima bastante daquela vivida por outros artistas da modernidade, anteriores e posteriores a ele, os quais também presenciaram situações sociais de absoluta dissonância entre a qualidade (e a consciência que tinham dessa qualidade) de suas aquisições e o desprezo social de que foram vítimas ao longo de toda a vida, tais como aconteceu a Charles Baudelaire, Paul Verlaine, Vincent van Gogh, Paul Cézanne, Antonin Artaud e tantos outros, chegando aos tempos atuais. 
a originalidade de uma sociologia que se constitui a partir da análise dos afetos, emoções e sentimentos que envolvem todos os indivíduos, mas que até o advento da obra de Elias não haviam sido considerados.

Nesse aspecto, para Heinich, a sociologia de Elias convida o pesquisador a adentrar por campos e temas da análise que permitem fundamentar, por sua vez, a reflexão sobre Mozart, ancorando-a na complexidade das relações que se dão entre os chamados grupos estabelecidos e os grupos outsiders, num processo que envolve, principalmente, enfrentar os problemas do controle das emoções e da balança de poder. Na análise de tal binômio, segundo Elias, deve-se chamar a atenção para a "curiosa fixação dos desejos dos outsiders pelo reconhecimento e aceitação do establishment que faz com que tal objetivo se transforme em foco de todos os seus atos e desejos, sua fonte de significado" (Elias, 1995a, p. 39), tornando-se objeto de desejo e de busca da referida aceitação do outro.

Tais conflitos entre partes se apresentam simplesmente porque um grupo se considera superior ao outro ou detém um volume maior de influência, status social e acesso ao bem-estar, provocando reações e ressentimentos entre subalternizados ou despossuídos. No caso em tela, Mozart encarna, com sua trajetória, diversos exemplos desse comportamento e essa insatisfação, que redundam em revolta e insubordinação aos padrões da corte, à qual gostaria de pertencer e da qual esperava reconhecimento. Numa carta endereçada ao pai, por exemplo, demonstra o conflito, revelando a flagrante dificuldade que tinha para aceitar a condição:

\footnotetext{
Na próxima segunda feira completarão seis semanas que estarei fora de Salzburgo. Sabe, meu querido pai, é somente para lhe agradar que permaneço lá, já que, por Deus, se tivesse seguido minha inclinação, um dia antes de partir teria limpado meu traseiro com meu último contrato, pois lhe juro por minha honra que não é Salzburgo, mas o príncipe e sua presunçosa nobreza que a cada dia se tornam mais intoleráveis para mim. Portanto, eu ficaria encantado se ele me mandasse dizer por escrito que não precisaria mais de meus serviços. (Mozart, W. A., apud Elias, 1995a, p. 113).
}

Esse episódio se refere a um desentendimento que pôs em atrito o músico e o arcebispo de Salzburgo, seu empregador, e que foi intermediado pelo pai. Trata-se, pois, claramente, de uma relação de disputa entre os primeiros, na qual o superior, por intermédio de Leopold Mozart, deixa claro que a insubmissão não seria tolerada, a despeito da alegação e da justificativa de Mozart de que necessitava mais tempo para terminar uma composição da qual estava encarregado. Noutra carta, Mozart escreve: "Sempre fico feliz quando tenho algo para compor, porque afinal de contas, essa é minha única delícia e paixão" (apud Elias, 1995a, p. 92). Ao longo do tempo, o conflito permanece, revelando o equilíbrio de forças representado por uma balança de poder que se constituía de relações tensas de dominação, submissão, atrito e também insubordinação. Essas relações não se manifestam somente na experiência de Mozart na corte, mas surgem em todas as configurações que envolvem exercício de poder e competição por status e ascensão social.

Desse modo, perceber a estreita e indissociável relação que há entre o indivíduo, a obra e o modelo de configuração social ao qual pertence, para Elias, é fundamental. Aqui, 
se discutirmos alguns aspectos da sua aproximação com o Mozart outsider e marginal, caminharemos então pelo terreno autobiográfico, que abrange a identificação do sociólogo com o artista, subsumindo, especialmente, as origens e os grupos aos quais Mozart pertenceu como músico e burguês de corte, e Elias como judeu alemão, vivendo entre duas culturas com especificidades próprias e frequentemente conflitantes.

Neste passo, perguntamo-nos sobre o modo como pensava o Elias outsider e o modo como construiu sua teoria, enfocando os processos de controle e autocontrole das emoções, a contenção da violência coletiva e individual e a monopolização da violência. Tudo mostra que os seres humanos, nos espaços que frequentam ou a que pertencem e nos quais circulam ao longo da vida, seja coletiva ou individualmente, estão sujeitos a processos determinantes e constitutivos de personalidade, civilidade e sociabilidade, bem como são movidos pelo desejo e pela necessidade de existir e se estabelecer socialmente ${ }^{14}$. Quanto a estes, Elias acredita que

para se compreender alguém, é preciso conhecer os anseios primordiais que este deseja satisfazer. A vida faz sentido ou não para as pessoas, dependendo da medida em que elas conseguem realizar tais aspirações. Mas os anseios não são definidos antes de todas as experiências. Desde os primeiros anos de vida, os desejos vão evoluindo, através do convívio com outras pessoas, e vão sendo definidos, gradualmente, ao longo dos anos na forma determinada pelo curso da vida; algumas vezes, porém, isso ocorre de repente, associado a uma experiência especialmente grave. Sem dúvida alguma, é comum não se ter consciência do papel dominante destes desejos. E nem sempre cabe à pessoa decidir se seus desejos serão satisfeitos; ou até que ponto serão, já que eles sempre estão dirigidos para outros, para o meio social. (Elias, 1995a, p. 13)

A sociologia figuracional, de cunho elisiano, permite, em seu setor, vislumbrar um campo novo de análises para a teorização e o estudo dos problemas humanos, no que diz respeito às relações de poder e aos processos de continuidade e ruptura que se dão no interior das relações. Para Elias (1994b), todos os fenômenos humanos (implicando reflexões sobre controle e autocontrole das emoções, caras ao autor) não apenas são passíveis de investigação, como também podem constituir o cerne de novas pesquisas, especialmente para aqueles que tentam compreender o modo como se configuram e a significação que assumem, nos jogos sociais, as relações entre estabelecidos e outsiders e os atritos delas decorrentes.

14 Constitui-se numa tarefa árdua escrever a biografia de um indivíduo, como tentativa de compreender sua obra ou relacionando-a à sua história de vida (no caso de um erudito, à sua trajetória acadêmica). De algum modo, esse tipo de pesquisa, quando fundado em depoimentos e entrevistas, desborda para as perspectivas da história oral, tomada como metodologia (Portelli, 2010; Bom Meihy \&Hollanda, 2015; Alberti 2011; Sarat \& Santos, 2010, entre outros) que pode garantir a legitimidade científica da investigação; mas remete também, nos casos de Mozart e Elias, aos estudos sobre memória e ressentimento que têm ganhado corpo atualmente (Ansar, 2001; Bresciani \& Naxara, 2001; Konstan, 2001; Pereira, 2013, 2015), como estratégias para compreender as relações dissimétricas que se estabelecem entre grupos de estabelecidos e ousiders, e sua relação com a história, para as quais a sociologia de Norbert Elias tem grandes contribuições a dar. 


\section{NORbERT Elias: outSIDER NÃO POR ACASO...}

"Visto objetivamente, eu era muito claramente um outsider (...) Era uma situação bastante estranha: politicamente, os judeus eram outsiders, e, ao mesmo tempo, faziam parte dos pilares da cultura alemã."

(Elias, 2001, p. 26)

Um olhar sobre a trajetória de vida de Norbert Elias demonstra que alguns aspectos de sua infância e de sua formação foram planejados no sentido de corresponderem aos valores e referências da cultura judaica, recebidos de seu grupo social. Suas experiências caminharam para cumprir as expectativas projetadas para uma criança abastada, filha única, imersa num processo de educação e formação erudita, tendo acesso a repertórios culturais, artísticos e educativos de prestígio na sua época, ou seja, um indivíduo com acesso a todas as condições materiais e culturais possíveis para a classe social a que pertencia, na Alemanha do início do século XX.

Uma consulta aos biógrafos informa, ainda, que até os dezoito anos Elias esteve incluído num mundo que lhe garantia proteção e segurança. Na infância, além dos professores particulares, teve acesso a uma boa escola — a melhor que sua condição lhe podia garantir, considerado o contexto familiar e econômico em que vivia: "En el Johannesgymnasium, el más distinguido colegio de Breslau, recebió una sólida educación germana, que inclúia sobre todo latín, griego, francés, matemáticas, ciência y clássicos de la literatura alemana como Goethe, Schiller y Heine" (Manzo, 2012, p. 17). Nesse sentido, sua existência deveria ter seguido uma trajetória esperada e previsível, ao alcance, pois, dos grupos estabelecidos dos judeus alemães desse período.

No entanto os planos e trajetórias mudaram para os indivíduos que faziam parte dessa cultura - historicamente, como dissemos, ligada à diáspora. Esse fato, que mudou em definitivo o curso da vida de Elias, alterou também o curso da vida de tantas famílias judias da Alemanha nas décadas de 30 a 40 do século XX, como decorrência, sobretudo, dos eventos brutais da Segunda Guerra Mundial (1939 a 1945). A guerra e a perseguição — desencadeando processos de consequências imprevisíveis - determinaram não só a mudança de curso uma trajetória pessoal, mas impuseram, por assim dizer, no caso do futuro sociólogo, uma direção às suas pretensões acadêmicas, com reflexos posteriores também em sua maneira de ver o mundo. Trata-se aqui de entender que as experiências vividas nessa época e nas seguintes, com todas as dificuldades que enfrentou para sobreviver e continuar existindo intelectualmente, ofereceram a Elias o estofo experiencial para construir uma teoria da análise sociológica na qual não deixou de considerar esses fatores, tomando-os como elementos de base na constituição do seu pensamento:

Tentando reconstruir em minha memória a maneira como meus pais e eu reagíamos a essa questão dos outsiders antes da I Guerra Mundial na Alemanha, constato que percebíamos perfeitamente a discriminação e a estigmatização do grupo ao qual pertencíamos - mas como através de um véu. Quando eu era criança, sabia a aversão e o ódio que dedicavam ao grupo ao qual eu pertencia, 
mas não fazia a menor ideia de sua amplitude. Aliás, meus pais e seus amigos não me davam explicação alguma sobre isso. Sentiam-se alemães e, de certo modo, procuravam não ver a realidade de frente. (Elias, 2001, p. 139)

Sobre esse aspecto Elias discorre em diversos trechos de suas obras. Com relação a si próprio, afirma: "É bastante provável que as experiências por que passei como judeu, na Alemanha, desde minha primeira infância, tenham contribuído para reforçar a atração que senti mais tarde pela sociologia" (Elias, 2001, p. 135). Ao fazer referência à infância, reconhece-a como um período fundante de sua vida. Por outro lado, informa também que estava "culturalmente muito ligado à tradição alemã", mas que tinha consciência de pertencer "pela estrutura de [sua] personalidade a um grupo minoritário desprezado" Elias (2001, p. 135). Esses aspectos - que mostram a importância que a análise das condições individuais de vida assume para Elias - reforçam a tese do indivíduo que se sentiu ou existiu como outsider desde suas origens. Neles, o autor sublinha, ao falar objetivamente da sua condição, o fato de os judeus serem politicamente outsiders e de que sua integração na sociedade alemã não estava dada ou concluída, não obstante atuarem como mentores, mecenas e sustentáculo da cultura germânica, no que diz respeito ao incentivo à produção do saber, das ciências e das artes em geral (comprovada pela abundância de intelectuais judeus na vanguarda do pensamento e da arte do século XX).

Em mais de um lugar, Elias afirma que o sinal mais forte da tradição judaica - a religião - não fazia parte de suas preocupações e que se considerava isento desse traço de religiosidade. No entanto reconhece que "o destino social do grupo exprimia-se de maneira evidente tanto no [seu] comportamento como na consciência que [ele] tinha de [si] mesmo e no [seu] pensamento" Elias (2001, p. 135). De igual modo, referindo-se à construção de seu pensamento, ao pensar sobre a sua ligação com a cultura judaica, também afirma: "Incluí muitos aspectos dessas experiências sociológicas, a teoria das relações entre grupos estabelecidos e outsiders $s_{2}$ pois o problema dos judeus alemães era efetivamente um problema de relações entre grupos estabelecidos e grupos outsiders" (Elias, 2001, p. 135). E avança externando a ideia de que "como muitos outros grupos outsiders, os judeus estavam excluídos, na Alemanha imperial, de toda série de promoções sociais" (Elias, 2001, p. 135), o que deixa claro o reconhecimento de sua condição de outsider desde a origem.

Assim, vendo-o assumir tal condição e suas implicações, podemos compreender a identificação de Elias com Mozart, até o ponto - conforme mencionado - de a obra que escreveu sobre o músico ser considerada "autobiográfica" pelos seus comentaristas. Podemos afirmar, com base na bibliografia (e em decorrência da presente reflexão), que Elias se sentia próximo a Mozart, no que concerne à condição outsider, vivendo também entre o reconhecimento e o desprezo, ao mesmo tempo que "preso" a uma condição de caráter imutável (que hoje chamaríamos de pertença sociocultural), tal como esse Mozart burguês de corte que, a despeito da sua revolta e dos seus esforços, não alteraria o seu estado. Tanto que, segundo pensamos, não foi possível a Elias prosseguir com seus estudos acadêmicos, pois, com o advento da guerra, aos judeus foi imposto um novo exílio obrigatório, para não falar do fardo e do horror do holocausto, o qual, com o manejo de leis e prisões arbitrárias, 
confinamentos em campos de concentração e assassinatos em massa, foi responsável pela expulsão e dizimação não só dos judeus na Alemanha, mas também de milhares de indivíduos de outras etnias ou grupos sociais ${ }^{15}$.

Assoma aqui o conceito, cunhado por Elias, do processo cego, que faz pensar que, mesmo quando se planejam e, aparentemente, se controlam todas as etapas, o risco da ruptura e da descontinuidade sempre está presente, transcendendo o âmbito das ações e cuidados do indivíduo. Por certo, podemos creditar às ações coletivas, de grupos, certas mudanças que, de tempos em tempos ao longo do processo histórico, sob condições específicas e por razões que não excluem o acaso, alteram o curso dos fenômenos sociais conforme aconteceu na vida do próprio Elias. Aparentemente planejada para seguir numa direção, sua existência sofreu rupturas em razão das condições políticas que envolveram e arrastaram o seu grupo de pertença: "Nunca fui nacionalista. Os nacionalistas na Alemanha eram evidentemente antissemitas - desde essa época - evidentemente" (2001, p. 25).

Podemos supor que a condição de outsider por nascimento, por cultura e pelo exílio imposto (tendo de deixar a Alemanha em 1933, para fugir ao nazismo, e se refugiar na França antes de se transferir para a Inglaterra), foi não só o resultado de um momento histórico e político específico, mas, sobretudo, se manifestou como consequência de um processo cego e não planejado, que mais tarde Elias descreverá como um elemento da sua obra:

A civilização não é 'razoável', nem 'racional' como também não é 'irracional'. É posta em movimento cegamente e mantida em movimento pela dinâmica autônoma de uma rede de relacionamentos, por mudanças específicas na maneira como as pessoas se veem obrigadas a conviver. (...) Porque é precisamente em combinação com o processo civilizador que a dinâmica cega dos homens, entremisturando-se em seus atos e objetivos, gradualmente leva a um campo de ação mais vasto para a intervenção planejada nas estruturas social e individual — intervenção baseada num conhecimento cada vez maior da dinâmica não planejada dessas estruturas. (Elias, 1993, p. 195)

A educação que Elias recebe na juventude e as condições sociais sob as quais vive levam-no, assim, a uma compreensão mais plena dos processos que busca descrever. De igual modo, dão-lhe uma consciência mais aguda do significado da sua própria contribuição intelectual e, desde cedo, dos problemas que deseja investigar. Segundo afirma, sua formação se direcionava, sobretudo, para a vida acadêmica, fato do qual desde criança teve clara percepção: "Soube desde cedo o que queria fazer: queria ir para a universidade ensinar e pesquisar. (...) Desde minha primeira infância e trabalhei tenazmente para atingir este objetivo, mesmo que às vezes me parecesse impossível" (Elias, 2001, p. 22). Deduz-se, pois, que seu objetivo não era escrever uma obra qualquer, mas alcançar uma relevância digna de nota, contribuindo, de algum modo, para ampliar o conhecimento que os homens

15 O avanço do nacional socialismo de Hitler e o nazismo da Alemanha na II Guerra Mundial foi responsável pela expulsão de inúmeras etnias e grupos que viviam na Europa, e não somente judeus. Incluiu também negros, ciganos, mulheres, homossexuais, intelectuais, estrangeiros e oposições partidária de um modo geral. 
têm de si (o que justifica dedicar a vida a um projeto intelectual). Obviamente, tal objetivo e a certeza que tem dele, quando referidos na altura dos 87 anos - já como um intelectual estabelecido e respeitado - têm um caráter retrospectivo, de "balanço" de vida; mas isso não exclui a possibilidade de pensarmos que essa certeza só poderia advir como resultado de um longo e perseverante esforço de autoanálise, autocompreensão e de compreensão dos outros (mesmo em se reconhecendo que, a muitos títulos, a confiança foi abalada com frequência, como o próprio Elias o admite, nas ocasiões em que se sentiu mais plenamente outsider ao longo de sua trajetória).

Quanto às ideias mais gerais sobre a formação e educação dos indivíduos e à sua relação com as estruturas sociais, podemos voltar, aqui, ao conceito de processo cego. É ele que nos permitirá, por exemplo, dizer que, a despeito de todo o planejamento e esforços que se empreendem no âmbito da educação das crianças, mesmo quando bem controlados, o processo não nos dá garantias de que atingiremos os objetivos, seja coletivamente, seja no plano da formação individual. Mesmo assim, apoiados em Elias, nada nos impede de afirmar que, se a infância é um período no qual o ser humano vivencia as suas primeiras experiências de mundo, é ela que fornece as bases para construir as noções de autonomia, consolidar os sentimentos de confiança, aceitação e estímulo, e para enfrentar os processos civilizadores no interior dos quais a trajetória de cada um se desenvolve. Sobre isso - a relação do processo educativo com o entorno social e do que este oferece ao indivíduo para que se oriente e subsista ao longo de sua trajetória - ao falar dos adultos (seus pais e outros membros de sua família), Elias se exprime de maneira incisiva: "Eles [os adultos] se ocupavam inteiramente de mim: eu me sentia completamente seguro. É por essa sensação de segurança que usufruí durante minha infância que explico minha perseverança" (Elias, 2001, p. 22)

A confiança foi necessária, quando circunstâncias decorrentes de processos não planejados o levaram ao exílio e à vida na obscuridade, contrariando aquilo para o qual a sua educação e os seus esforços o preparavam. Nesses momentos, em que se sentiu mais outsider (“... escrevia meus livros e ninguém prestava atenção em mim...”), a lembrança das origens, da proteção e da segurança juvenil o ajudaram a sustentar-se e a continuar. Tanto do ponto de vista da teoria, quanto do ponto de vista de uma percepção de si, a relevância que Elias atribui às experiências de infância, para além do determinismo, reforça a nossa premissa de que esse período da vida é fundamental na trajetória de todos os indivíduos, como um determinante que a sociologia se esforça hoje por compreender. Trata-se, afinal, não só de uma época em que famílias e adultos devem se tornar responsáveis, em maior ou menor grau, pela sobrevivência e educação dos pequenos - tanto nos espaços domésticos como nos institucionais. É um momento vital em que nossos recursos de sobrevivência, de sentimento e de adaptabilidade ao entorno social (relacionados à aquisição de habilidades socialmente úteis e, na linguagem de Elias, ao controle das emoções) tomam corpo: "Talvez eu possa formular da seguinte maneira: assim como os astrônomos descobriram que todo o universo repercute ruídos consecutivos ao Big Bang inicial, assim os homens trazem em si, no que diz respeito às suas vidas, uma intuição cuja origem remonta aos primeiros momentos passados com sua família" (Elias, 2001, p. 22). 
Portanto, do mesmo modo que reconhecem o lugar da educação e da formação do indivíduo na teoria sociológica, as formulações de Elias apontam para a compreensão de que os resultados, do ponto de vista de cada indivíduo, seguem cursos distintos, pois "o processo civilizador individual, tal como o social, segue em geral cegamente seu curso" (Elias, 1993, p. 2004). No seu caso, a existência oscilou, sempre, numa região fronteiriça, que separa o ser estabelecido do ser outsider, sem abrir mão de um projeto de vida pessoal e duradouro. Também podemos dizer que, ao tempo em que suas experiências de infância e juventude contribuem para dar forma e conteúdo às suas concepções, ter alcançado (depois de uma trajetória que incluiu, além de uma ruptura com suas referências familiares e alemãs - com consequências de longo prazo que levaram ao seu reconhecimento tardio - dar cursos em universidades, participar de grupos de trabalho e pesquisa acadêmica e publicar uma obra volumosa) um lugar como parte de um establishment acadêmico que só se efetivou na velhice (pois a primeira grande guerra foi a ruptura inicial do seu mundo protegido de Breslau, que o fez mudar completamente, segundo relata) lhe permite, em retrospectiva, compreender melhor o sentido dessa trajetória.

\section{CONSIDERAÇões FINAIS}

Nesta altura, podemos dizer que, vivendo como outsider, mas morrendo como parte do estableshiment acadêmico, Elias deu um fecho satisfatório à sua trajetória - diferentemente de Mozart que, morrendo jovem, não pôde cumprir por inteiro o arco de tudo aquilo que suas capacidades prometiam, não obstante o valor de quanto realizou. Do mesmo modo se pode dizer, de Elias, que inscreveu o seu nome no panteão da Sociologia do século XX, conforme o reconhecem teóricos do porte de Lewis Coser, Zygmunt Bauman, Anthony Giddens e outros. Quanto a isso, não há melhor maneira de sumarizar a sua trajetória do que com as palavras de Dirk Kaesler (citado num estudo introdutório ao pensamento de Elias por E. G. Manzo), estudioso de Weber, que viu nele um "sociólogo para la Europa del siglo XX y um sociólogo para el mundo en siglo XXI” (Manzo, 2012, p. 9).

Estabelecendo-se como intelectual por escolha acadêmica e profissional, para a qual se preparou desde a infância, independentemente das circunstâncias de nascimento que o fizeram outsider, sua determinação e confiança na ciência, na racionalidade e na capacidade humana de chegar ao esclarecimento pelo conhecimento o levaram a perseguir esse propósito como ideal que o manteve vivo, na expectativa de que seu pensamento seria reconhecido. Tal aspecto perpassa, como um subtexto profundo, toda a entrevista em que nos apoiamos para escrever este estudo: "Era uma condição sine qua non: ou eu triunfava ou desaparecia. Não tinha certeza absoluta, naturalmente, mas não duvidava nem um pouco de que minha obra um dia seria reconhecida como contribuição de qualidade ao saber da humanidade" (Elias, 2001, p. 22).

Finalmente, cumpre dizer que, ora estabelecidos, ora outsiders, o que distingue Elias de Mozart é, sobretudo, a possibilidade da longevidade, que dá à experiência do primeiro um teor que falta à do segundo, sem os tornar estranhos um ao outro. Mozart morreu sem 
provar o reconhecimento desejado, ao passo que Elias, vivendo por quase um século, teve oportunidade de vivenciar mais intensamente esse sentimento, mormente em seus últimos anos. Em especial, foi entre as décadas de 70 e 80 do século XX — quando tinha idade para se afastar e se aposentar - que os momentos mais intensos de sua carreira acadêmica se manifestaram. Nessas ocasiões, além de receber homenagens, realizou conferências, deu entrevistas, fez preleções sobre diversos temas em perspectiva pluridisciplinar, propôs revisões e testou sua teoria em aulas, debates e orientações acadêmicas, experimentando assim, tardiamente, o resultado daquilo para o qual se preparara durante toda a vida: ou seja, tinha se tornado um nome de referência.

Podemos nos perguntar sobre o motivo pelo qual Elias não desistiu, como o fez Mozart ao sucumbir à doença, ao desânimo e à depressão que o mataram aos 35 anos. Segundo o declara, o sociólogo estava afiançado em seus propósitos, mas também nas bases emocionais e psíquicas que suas experiências de infância lhe proporcionaram, consideradas sólidas e permanentes. Isso lhe permitiu, para usarmos um termo que hoje está em voga, "ressignificar" o próprio passado não uma, mas diversas vezes ao longo de sua vida, e disso é ele mesmo quem nos fala em sua tocante entrevista: "Tenho a intuição que me dá segurança de que tudo irá bem; enfim, atribuo isso à enorme sensação de segurança que usufruí como filho único, graças a amor de meus pais" (Elias, 2001, p. 22).

\section{REFERÊNCIAS}

ALBERTI, V. Histórias dentro da História. IN: PINSKY, Carla Bassanezi et al. Fontes Históricas. 3. ed. São Paulo: Contexto, 2011. p. 155-202.

ANSART, P. História e Memória dos Ressentimentos. In: BRESCIANI, S. E NAXARA, M. (Org.) Memória e (Re)Sentimento: indagações sobre uma questão sensível. Campinas-SP: Editora da UNICAMP, 2001. p. 15-36.

ARIÈS, P. História social da criança e da família. Trad. Dora Flaksman. 2. ed. Rio de Janeiro: LTC Editora, 1981.

BOM MEIHY, J. C. S. \& HOLLANDA, F. História oral: como fazer como pensar. São Paulo: Contexto, 2015.

BRESCIANI, S. \& NAXARA, M. (Org.) Memória e (Re)Sentimento: indagações sobre uma questão sensível. Campinas-SP: Editora da UNICAMP, 2001.

BLOT, J. Wolfgang Amadeus Mozart. Buenos Aires: Editorial El Ateneo, 2015.

ELIAS, N. La civilización de los padres. In: WEILER, V. (Org.) La civilización de los padres y outros ensayos. Bogotá, Editorial Norma. 1998.

. O processo civilizador. Rio de Janeiro: Jorge Zahar, 1994a, v. 1.

. O processo civilizador: formação do Estado e civilização. Rio de Janeiro: Jorge Zahar, 1993, v. 2. 
. A sociedade dos individuos. Rio de Janeiro: Zahar, 1994b.

. Elias por ele mesmo. Rio de Janeiro: Zahar, 2001.

. Mozart: sociologia de um gênio. Rio de Janeiro: Zahar, 1995a.

. Mi trajectoria intelectual. Barcelona, Peninsula, 1995b.

GEBARA, A. Conversas sobre Norbert Elias. Piracicaba-SP: Biscalchin Editor, 2005.

GEBARA, A.; WOUTERS, C. (Orgs.) O controle das emoções. João Pessoa: Editora Universitária da UFPB, 2009.

HEINICH, N. A sociología de Norbert Elias. Bauru-SP: EDUCS, 2001.

. Norbert Elias: historia y cultura en Ocidente. Buenos Aires: Nueva Visión,

1999.

KAPLAN, C. \& ORCE, V. (orgs.). Poder, práticas sociales y Proceso Civilizador: los usos de Norbert Elias. Buenos Aires: Centro de Publicaciones Educativas y Material Didáctico, 2009.

KAPLAN, C. V. (Org.). Comportamiento individual y estructura social: cambios y relaciones: una lectura desde Norbert Elias. In: KAPLAN, C. V. (Org.). La civilización en questión. Buenos Aires: Miño y Dávila, 2008.

KONSTAN, D. Ressentimento - História de uma emoção. In: BRESCIANI, S. \& NAXARA, M. (Org.) Memória e (Re)Sentimento: indagações sobre uma questão sensível. Campinas-SP: Editora da UNICAMP, 2001. p. 59-81.

MANZO, E. G. Breve introducción al pensamiento de Norbert Elias. México DF: Universidad Autónoma Metropolitana San juan de Dios, 2012.

PADALE, J. Los protagonistas: Mozart. Buenos Aires: Cinco ECSA, 2004.

PEREIRA, M. J. Os imigrantes de origem germânica no Paraná: debate sobre a presença teuta no Estado In: Imigração e colonização: conflitos pela terra no Paraná e São Paulo entre os séculos XIX e XX. Guarapuava-PR: Editora Unicentro, 2015. p. 115-156.

PEREIRA, M. J. Autoritarismo e repressão no Paraná durante o Estado Novo: a ação do DOPS/PR contra os inimigos da nação. In: Sombras autoritárias e totalitárias no Brasil: integralismo, fascismos e repressão política. Maringá: EDUEM, 2013. p. 193-222.

PEREZ RIVERA, H. E. Norbert Elias: un sociólogo contemporáneo. In: Teoria y método. 2. ed. Medellín, Colômbia: La carretera Editores, 2010.

PORTELLI, A. Ensaios de história oral. São Paulo: Letra e Voz, 2010.

QUINTANEIRO, T. Processo Civilizador: sociedade e indivíduo na teoria sociológica de Norbert Elias. Belo Horizonte-MG: Argumentum, 2010.

SARAT, M. \& SANTOS, R., História oral como fonte. In: COSTA, C. J. et al. (Orgs.) Fon- 
tes e métodos em história da educação. Dourados/Maringá: EdUFGD/UEM, 2010

SARAT, M. Contribuições de Norbert Elias aos estudos da Infância e Processo Civilizador. In: COSTA, C; SARAT, M; GEBARA, A. (Orgs.) Leituras de Norbert Elias: Processo Civilizador, educação e fronteiras. Maringá-PR: EdUEM, 2014.

. A infância de Mozart e memórias de velhos; contribuições de Norbert Elias. Revista Intermeio do Programa de Pós-Graduação em Educação. Campo Grande, Editora da UFMS, v. 14 n. 28. jul/dez 2008. p. 102-120.

. Reflexões sobre infância: Elias, Mozart e memórias de velhos. Anais do IX Simpósio Internacional Processo Civilizador: Tecnologia e Civilização. Dourados: EdUFGD, 2005.

. Relações entre gerações e processos civilizadores. In GOETTERT, J. D; SARAT, M. (Orgs.) Tempos e espaços civilizadores: diálogos com Norbert Elias. Dourados-MS: EdUFGD, 2009.

WEILER, V. Presentación. In: WEILER, V. (Org.) La civilización de los padres y outros ensayos. Bogotá: Editorial Norma, 1998.

ZABLUDOVSKY, G. Introducción/Prólogo. In: ELIAS, N. El proceso de la civilización; investigaciones sociogenéticas y psicogenéticas. 3. ed. México: FCE, p. 2009.

. Norbert Elias y los problemas de la sociología. México: FCE, 2007.

\section{Magda SARAT}

Doutora em Educação pela Universidade Metodista de Piracicaba (UNIMEP) e Pós-doutora pela Universidade de Buenos Aires (UBA/Argentina). Professora Associada da Faculdade de Educação da Universidade Federal da Grande Dourados (UFGD), Docente do Programa de Pós-Graduação em Educação (UFGD) e Líder do Grupo de Pesquisa Educação e Processo Civilizador (GPEPC/UFGD).

magdaoliveira@ufgd.edu.br

\section{Renato Suttana}

Doutorado em Letras-Literaturas de Língua Portuguesa pela Universidade Estadual Paulista Júlio de Mesquita Filho (UNESP). Pós-doutorado em Letras pela Universidade de Buenos Aires (UBA). Professor Associado da Faculdade de Comunicação Artes e Letras da UFGD. Docente do Programa de Pós-Graduação em Letras da UFGD. Escritor, mantém na Internet, no endereço http://www.arquivors.com um sítio de literatura com publicações de autoria própria e de colaboradores.

renatosuttana@ufgd.edu.br

Submetido em:19-8-2017

Aceito em:10-11-2017 